\title{
Resenha
}

\section{Educação escolar e pesquisa na Teoria Histórico-Cultural}

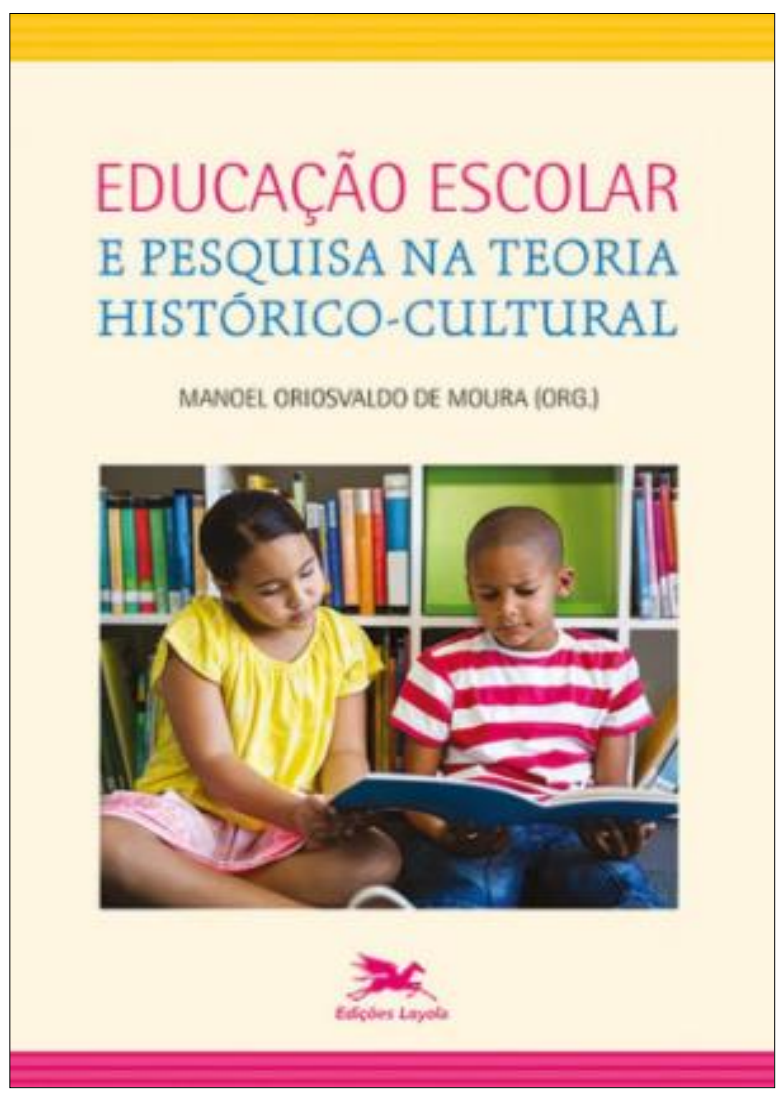

Lóren Grace Kellen Maia Amorim ${ }^{1}$

MOURA, Manoel Oriosvaldo de. Educação escolar e pesquisa na teoria histórico-cultural. São Paulo: Edições Loyola, 2017.

$\mathrm{Na}$ presente resenha, tem-se a intenção de apresentar o livro organizado por Manoel Oriosvaldo de Moura, Educação escolar e pesquisa na teoria histórico-cultural, São Paulo: Edições Loyola, 2017. Ressalta-se que o tema apresentado, na perspectiva teórica explicitada, vem ganhando espaço nas

1 Doutoranda do Programa de Pós-Graduação em Educação, Faculdade de Educação, Universidade Federal de Uberlândia. Professora da Rede Municipal de Ensino de Uberlândia. ORCID: https://orcid.org/0000-0002-7086-0159. E-mail: lorengkma@gmail.com. 
discussões sobre educação e a obra, sem sombra de dúvidas, tem uma grande contribuição para os estudiosos dessa temática. Justifica-se, assim, a sua divulgação devido à importância para as pesquisas no campo da Didática, do ensino e da aprendizagem de Matemática.

O organizador do livro, Manoel Oriosvaldo de Moura, é professor titular da Faculdade de Educação da Universidade de São Paulo (FEUSP) e do Programa de Pós-graduação da mesma instituição. Atua na área de Educação Matemática, com foco em metodologia do ensino de Matemática, formação de professores e teoria da atividade. É coordenador do Grupo de Estudos e Pesquisa sobre Atividade Pedagógica (GEPAPe) ${ }^{2}$. Desse grupo participam pesquisadores de diferentes instituições brasileiras, estudantes de pósgraduação e graduação e professores de educação básica.

O livro Educação escolar e pesquisa na teoria histórico-cultural, apresenta o resultado dos estudos empreendidos pelo GEPAPe que desenvolve ações e investigações referente à Atividade Pedagógica. É redigido por participantes do grupo e está dividido em sete capítulos, nos quais: são explicitados os métodos e as metodologias das pesquisas em Educação na Teoria HistóricoCultural; é discutida a pesquisa em Educação como atividade baseadas nos pressupostos teórico-metodológicos da Teoria Histórico-Cultural; é apresentada a objetivação do ensino e o desenvolvimento do modo geral da aprendizagem da Atividade Pedagógica; é anunciado as relações entre os processos de apropriação das significações da Atividade Pedagógica e o sentido pessoal a essa atividade, ambos presentes na Teoria da Atividade de Leontiev; é aprofundado o estudo sobre as relações entre o movimento histórico e lógico de um conceito, desenvolvimento do pensamento teórico e conteúdo escolar; é articulada a proposição Gepapeana e Davidoviana, no contexto da história virtual "Verdim e seus amigos" e, por último, são revelados os elementos que constituem os processos intencionais de formação do professor na licenciatura e no decorrer da docência.

A leitura desse livro proporciona ao leitor vislumbrar as singularidades dos métodos e das metodologias em pesquisas educacionais na Teoria Histórico-

2 http://www2.fe.usp.br/ gepape/. 
Cultural, permitindo ainda compreender que na pesquisa em Educação o objeto central é a Atividade Pedagógica.

$\mathrm{Na}$ obra, o leitor se depara com as particularidades da Atividade Orientadora de Ensino, reverbera sobre os conceitos de significação social e sentido pessoal, compreende a importância do movimento lógico-histórico para a apropriação de conceitos teóricos no processo de ensino e aprendizagem de matemática e, vislumbra e reconhece que o sujeito em formação se realiza em espaços coletivos e na interação com o meio social.

Considerando o processo histórico, com objetivo de compreender a lógica do movimento da pesquisa educacional, Wellington Lima Cedro e Carolina Picchetti Nascimento, no primeiro capítulo "Dos métodos e das metodologias em pesquisas educacionais na teoria histórico-cultural”, baseados em Kopin (1978), adotam o lógico como a relação dialética e histórica. No decorrer do capítulo apresentam o movimento de constituição dos paradigmas positivistas e humanistas na pesquisa em Educação, sendo o segundo paradigma destaque no campo educacional. No paradigma humanista a abordagem qualitativa é um denominador comum presente nas maiorias das pesquisas, no qual o processo histórico dos métodos e das estratégias metodológicas de investigação colocam essa perspectiva em movimento. Os autores anunciam que a Teoria Histórico-Cultural se vincula ao paradigma humanista, porém essa contempla método de investigação que se diferencia das demais teorias inclusas na mesma corrente. Nessa teoria o método de investigação está arraigado no método filosófico materialista histórico e dialético, no qual o fenômeno é estudado considerando a sua totalidade e constitui-se em "premissa e produto, ferramenta e resultado" (p.32) do método de investigação. Assim, os autores indicam que assumir a Teoria Histórico-Cultural nas pesquisas em Educação é uma necessidade teórica e metodológica. Teórica com a finalidade de conhecer os processos de desenvolvimento do psiquismo humano na busca de corroborar para o seu desenvolvimento total e, metodológica com intuito de elaborar um método científico da Pedagogia que contribua para que o estudante supere as relações objetivas que dificultam a formação da personalidade, que se concretiza no desenvolvimento do pensamento teórico (DAVIDOV, 1988). 
No segundo capítulo intitulado "Dos princípios da pesquisa em Educação como atividade" as autoras Elaine Sampaio Araujo e Silvia Pereira Gonzaga de Moraes, explicam que a pedagogia possui seu próprio objeto de investigação que se diferencia do proposto na Psicologia, sendo a Atividade Pedagógica o objeto central da pesquisa em Educação. Para organização e compreensão de tal objeto utilizam como instrumento os pressupostos da Teoria Histórico-Cultural abarcados na Psicologia Histórico-Cultural sobre o processo de desenvolvimento das funções psicológicas superiores. No desenrolar do capítulo, as autoras consideram que a pesquisa em Educação é uma atividade, com isso determinam as ações que vão da apreensão da realidade às análises para explicar os fenômenos e a sistematização e exposição dos resultados alcançados.

Apoiados na Teoria da Atividade proposta por Leontiev (1978), Manoel Oriosvaldo de Moura, Marta Sueli de Faria Sforni e Anemari Roesler Luersen Vieira Lopes, no capítulo 3, "A objetivação do ensino e o desenvolvimento do modo geral da aprendizagem da atividade pedagógica”, apresentam como hipótese que o ensino como atividade se concretiza na Atividade Orientadora de Ensino (MOURA, 2001; MOURA et al., 2010), cujo foco está no processo de aprendizagem do professor no desenvolvimento da Atividade Pedagógica. Os autores ressaltam que a intencionalidade do professor, no que tange a objetivação de sua atividade que é o ensino, está relacionada com às ações e operações com intuito de promover a aprendizagem de um conceito, permitindo que o professor ao interagir com estudante, reflita, analise e sintetize o modo de (re)organizar a sua Atividade Pedagógica. Os autores enfatizam que a Atividade Pedagógica permite a união de dois motivos que no primeiro momento são distintos, sendo esses "formado pela atividade de ensino, do professor, e a atividade de aprendizagem, do aluno" (p. 73), sendo está última o instrumento de avaliação da atividade de ensino. Essas atividades são mediadas pela Atividade Orientadora de Ensino (AOE), que contempla a unidade teórico-prática, visto que nessa o professor para alcançar determinado produto irá mobilizar seus conhecimentos acerta da Educação, dos conteúdos escolares, dos processos de desenvolvimento e aprendizagem e os modos de ação para a sua realização. Os autores citam que AOE pode ser 
concretizada por meio de uma situação desencadeadora da aprendizagem que contemple a importância histórica do conceito e como esse se desenvolveu logicamente. Nessa perspectiva, considerando a formação do professor, foi apresentada uma proposta que pode permitir ao professor compreender o desenvolvimento lógico histórico do conceito de fração e a organização da atividade de ensino atentando para esse desenvolvimento e para o processo de significação, por meio da história virtual do conceito vivenciado por Cordasmil.

Assumindo que os objetivos da escola sejam de superação da alienação e a caminho para a emancipação do sujeito, no capítulo IV, "Significação e sentido da psicologia histórico-cultural: implicações para a educação escolar”, Débora Cristina Piotto, Flávia da Silva Ferreira Asbahr e Flávio Rodrigo Furlanetto, explicitam os conceitos de significação social e sentido pessoal, presentes nas obras de Vigotski e Leontiev e enfatizam o papel da escola na educação no sentido pessoal, ressaltando o envolvimento subjetivo com o aprender. Os autores relatam a importância de compreender os conceitos de sentido e de significação, para que os mesmos não sejam utilizados de forma banalizadas, isto é, faz-se importante durante a pesquisa explicar quais conceitos são adotados e em qual base teórica estão fundamentados. Em relação a esses conceitos, os autores se apoiam em Leontiev (1978) considerando que o sentido pessoal é formado no processo de desenvolvimento da atividade do sujeito e que a maneira como o indivíduo se apropria (ou não) de determinadas significações está relacionada ao interesse desse, ou seja, depende do sentido pessoal que elas apresentam para o sujeito. Diante disso, a Atividade Pedagógica passa a ser organizada de forma que gere no sujeito uma necessidade, que desencadeará o motivo para agir. Assim, os autores anunciam a relevância da conscientização, na perspectiva de que a atividade de estudo passe a assumir um sentido pessoal, convertendo-se na fonte do autodesenvolvimento delas.

No capítulo V intitulado "Relações entre movimento histórico e lógico de um conceito, desenvolvimento do pensamento teórico e conteúdo escolar" as autoras Maria Lucia Panossian, Vanessa Dias Moretti e Flávia Dias de Souza, destacam o processo de apropriação de conceitos teóricos na escola, ressaltando a 
necessidade de que os problemas de aprendizagem da Matemática contemplem o movimento histórico e lógico dos conceitos, vinculados ao movimento filogenéticos de desenvolvimento humano e ao movimento ontogenéticos de apropriação conceitual pelos sujeito mediado pela cultura.

As autoras tomam o movimento histórico e lógico dos conceitos como "ponto de análise", visto que essa posição "permite identificar os elementos essenciais inerentes a determinada forma de conhecimento, constituindo assim um "objeto de ensino" (p. 139), que por sua vez precisa perpassar vários "conteúdos de ensino" ou "tópicos de ensino" na organização curricular escolar. Analisam os conceitos de álgebra, reconhecendo a importância do movimento histórico e lógico desses para constituição de um objeto de ensino, reforçando a necessidade do conceito ser central nos processos de ensino e aprendizagem algébricos. Assim, indicam ser fundamental que aprendizagem seja organizada com base na elaboração de relações conceituais e estruturais do assunto/conteúdo de ensino.

O leitor que deseja refletir sobre as viabilidades de apropriação dos conhecimentos científicos que contribuem para o desenvolvimento do pensamento teórico (DAVÝDOV, 1988) no processo de ensino e aprendizagem, encontrará no capítulo 6 intitulado "O Ensino de Matemática no primeiro ano escolar: uma articulação entre a proposição Gepapeana e a Davydoviana", escrito por Josélia Euzébio da Rosa e Ademir Damazio, detalhes relacionados à compreensão do conceito de atividade de estudo proposta por Davýdov (1999). Além disso, terá oportunidade de conhecer como os autores articularam as proposições da atividade de estudo com a história virtual conhecida como "Verdim e seus amigos", que contempla a essência do conceito teórico de medida e possibilita a reprodução histórica do conceito de número em seu estágio atual. Os autores apresentam as tarefas particulares presentes nas seis ações de estudos propostas por Davýdov (1999), que partem da história virtual, a serem desenvolvidas pelos estudantes com a orientação do professor.

Admitindo que os processos de mudança da prática dos professores dependem de mudanças internas, no último capítulo "A atividade de formação do professor na licenciatura e na docência”, Marisa da Silva Dias e Neusa Maria 
Marques de Souza buscam na Teoria Histórico-Cultural parâmetros que permitam compreender os fenômenos no processo formativo, considerando a dimensão humana de formação dos indivíduos que, como seres sociais, organizam sua atividade nas relações subjetivas e objetivas contempladas nas ações humanas. As autoras buscam no desenrolar do capítulo alinhavar os elementos presentes no processo de conscientização dos sujeitos em formação para o ensino, com olhar para os cursos de licenciatura e no decorrer do exercício na docência. Destacam que a atividade do sujeito-professor em formação, no curso inicial e na docência, acontece em espaços coletivos e na relação do sujeito com o meio social.

O livro organizado por Manoel Oriosvaldo de Moura e escrito a várias mãos demonstra que a Atividade Pedagógica, fundamentada na Teoria Histórico-Cultural, exige esforço coletivo e necessita de um método que contribua na análise dos elementos que a constitui, visto que essa é compreendida pelo GEPAPe como a unidade entre a atividade de ensino e a atividade de aprendizagem.

Assim, para o desenvolver o pensamento teórico dos estudantes, cientificamente orientado, torna-se importante que o professor intencionalmente organize seu ensino de modo a contemplar a unidade teórico-prática do conceito, o movimento lógico-histórico, as ações e operações que sejam consoantes com os objetivos pedagógicos e que permita aos sujeitos envolvidos a apropriação da cultura e dos conhecimentos acumulados historicamente.

A leitura do livro, viabiliza compreender a Educação escolar em um sentido mais amplo, ao considerar o estudante na sua totalidade e coloca o leitor na necessidade de aprofundar alguns conceitos retratados. Isso não significa que os autores não apresentaram os temas de forma coesa e clara, mas que o processo de ensino, aprendizagem e desenvolvimento exige uma compreensão mais profunda do desenvolvimento humano.

Boa leitura! 


\section{Referências}

DAVIDOV, V. V. Tipos de generalización em la enseñanza. Havana: Pueblo y educación, 1978.

DAVIDOV, V. V. La enseñanza escolar y el desarollo psíquico: investigación teórica y experimental. Moscou: Progresso, 1988.

DAVÝDOV, V. V. O que é a verdadeira atividade de aprendizagem? Trad. Cristina Pereira Furtado. Revisão da tradução José Carlos Libâneo e Raquel A. Marra da Madeira Freitas. 1999. (What is real learning activity).

KOPIN, P. V. A. A dialética como lógica e teoria do conhecimento. Rio de Janeiro: Civilização Brasileira, 1978.

LEONTIEV, A. N. O desenvolvimento do psiquismo. Lisboa: Horizonte Universitário, 1978.

MOURA, M. O. A atividade de ensino como ação formadora. In: CASTRO, A. D.; CARVALHO, A. M. P. de (org.). Ensinar a ensinar - didática para a escola fundamental e média. São Paulo: Pioneira Thomson Learning, 2001, 143-162.

MOURA, M. O. de et al. A atividade orientadora de ensino como unidade entre ensino e aprendizagem. In: MOURA, M. O. de (org.). A atividade pedagógica na teoria histórico-cultural. Brasília: Liber Livro, 2010. DOI: https://doi.org/10.7213/rde.v10i29.3094. 